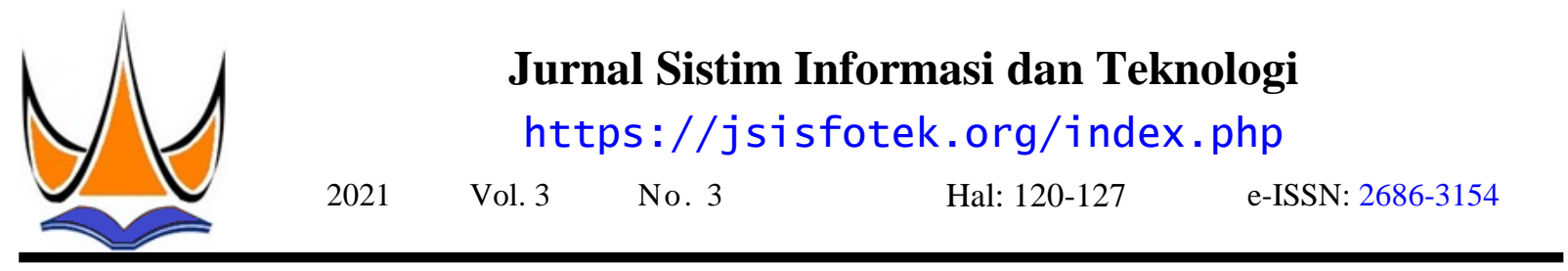

\title{
Prediksi Hasil Belajar Siswa Secara Daring pada Masa Pandemi COVID-19 Menggunakan Metode C4.5
}

\author{
Yetti Fitriani $^{1 凶}$, Sarjon Defit $^{2}$, Gunadi Widi Nurcahyo ${ }^{3}$ \\ ${ }^{1}$ SMK Negeri 2 Padang Panjang \\ ${ }^{2,3}$ Universitas Putra Indonesia YPTK Padang \\ yetti.fitriani@gmai1.com
}

\begin{abstract}
Student learning in schools has changed since the Covid-19 pandemic. Student learning in normal conditions is carried out face-to-face and turns into online or online learning. The research was conducted to predict student learning outcomes during the COVID-19 pandemic so that the results of this study can be used as a reference in policymaking in schools. The C4.5 method was used in the study to classify the data for class XII of the Multimedia Department at SMKN 2 Padang Panjang and the classification results could predict student learning outcomes during the pandemic. Processed student value data were taken from 1 (one) subject as the research data sample. Analysis of the value of student learning outcomes using the C4.5 Method to obtain new knowledge from student learning outcomes data carried out during the COVID-19 pandemic. The data analyzed consisted of attributes of attendance, assignments, daily tests, and test scores which influenced the decision criteria for student learning outcomes in online learning. The learning outcome decision criteria consist of "Satisfactory" and "Not Satisfactory" which refer to the Minimum Completion Criteria. Tests conducted on the training data of learning outcomes show that the value of the Daily Test is the most influential attribute in decision making. Implementation of the results using the RapidMiner Studio 9.2.0 software and produces an accuracy of $83.33 \%$ of the test data testing with the rules of data analysis training results. The results of the $\mathrm{C} 4.5$ classification testing method in this study can be used to predict student learning outcomes. The test results with an accuracy of $83.33 \%$ can be recommended to help schools in making policies.
\end{abstract}

Keywords: Online Learning, Pandemic COVID-19, Data Mining, C4.5, Rules.

\begin{abstract}
Abstrak
Pembelajaran siswa di sekolah mengalami perubahan sejak pandemi Covid-19.Pembelajaran siswa pada kondisi normal dilaksanakan secara tatap muka berubah menjadi pembelajaran Online atau Dalam Jaringan (Daring). Penelitian dilakukan untuk memprediksi hasil belajar siswa pada masa pandemi COVID-19 sehingga hasil penelitian bisa digunakan untuk menjadi acuan dalam pengambilan kebijakan di sekolah.Metode C4.5 digunakan pada penelitian untuk mengklasifikasi data nilai siswa kelas XII Jurusan Multimedia di SMKN 2 Padang Panjang dan hasil klasifikasi dapat memprediksi hasil belajar siswa pada masa pandemi. Data nilai siswa yang diolah diambil dari 1 (satu) mata pelajaran sebagai sampel data penelitian. Nilai hasil belajar siswa dianalisa menggunakan Metode C4.5 untuk mendapatkan pengetahuan baru dari data nilai hasil belajar siswa yang dilaksanakan pada masa pandemi COVID-19.Data yang dianalisa terdiri dari atribut absensi, tugas, Ulangan Harian (UH) dan nilai ujian yang mempengaruhi kriteria keputusan hasil belajar siswa pada pelajaran yang dilaksanakan secara daring. Kriteria keputusan hasil belajar terdiri dari "Memuaskan" dan "Kurang Memuaskan"

] yang mengacu kepada Kriteria Ketuntasan Minimal (KKM). Pengujian yang dilakukan terhadap datatraining hasil belajar menunjukkan bahwa nilai Ulangan Harian (UH) merupakan atribut yang paling mempengaruhi terhadap keputusan. Implementasi hasil menggunakan Software Rapid Miner Studio 9.2.0 dan menghasilkan akurasi sebesar 83,33\% dari pengujian data testing dengan rule-rule hasil analisadata training. Hasil pengujian klasifikasi metode C4.5 pada penelitian ini bisa digunakan untuk memprediksi hasil belajar siswa.Hasil pengujian dengan akurasi sebesar 83,33\% sudah dapat direkomendasikan untuk membantu pihak sekolah dalam membuat kebijakan.
\end{abstract}

Kata kunci: Daring, Pandemi COVID-19, DataMining, C4.5, Rule.

(C) 2021 JSisfotek

\section{Pendahuluan}

Pandemi Covid-19 telah membuat banyak perubahan pada pola kehidupan di masyarakat.Dunia pendidikan merupakan salah satu bidang yang mengalami perubahan sangat signifikan.Sistem-sistem yang dilaksanakan pada bidang pendidikan berubah menyesuaikan dengan kondisi yang ada ditengah pandemi Covid-19. Perubahan yang sangat drastis untuk pendidikan terjadi pada proses pembelajaran siswa yang biasanya dilaksanakan di kelas secara tatap muka beralih pada metode online atau dalam jaringan yang biasanya dikenal dengan sebutan daring.
SMKN 2 Padang Panjang sejak pandemi Covid-19 melaksanakan pembelajaran siswa secara daring. Pembelajaran Daring yang dilaksanakan di SMKN 2 Padang Panjang dilakukan dengan menggunakan beberapa aplikasi maupun portal untuk mendukung terlaksananya pembelajaran dalam jaringan seperti WhatsApp, Telegram, Google Classroom, dan beberapa aplikasi lain yang tersedia dan sudah melakukan kerjasama dengan Kemendikbud.

Knowledge Discovery in Database (KDD) yang biasa disebut dengan Data Mining menghasilkan pola yang sangat berharga dari data yang berukuran besar. KDD 
menggunakan beberapa metode untuk mendapatkan 19 yang disebabkan oleh berbagai kondisi lingkungan informasi baru, di antaranya yang sering digunakan keluarga yang tidak kondusif [15].

metode klasifikasi dengan Algoritma C4.5.

Pendidik dan peserta didik banyak yang belum siap

KDD diartikan sebagai keseluruhan proses non-trivial menghadapi revolusi industri 4.0, tetapi dengan adanya untuk mencari dan mengidentifikasi pola (pattern) pembelajaran daring pada masa pandemi COVID-19 dalam data, di mana pola yang ditemukan bersifat sah, memaksa semua orang untuk siap menghadapi baru, dapat bermanfaat dan dapat dimengerti [1]. Data perkembangan teknologi [16]. Beragam cara siswa Mining sering dianggap sama dengan Knowledge dalam menyikapi dan mengikuti pembelajaran daring, Discovery in Database (KDD), padahal Data Mining di mana dapat mempengaruhi hasil belajar siswa adalah salah satu tahap dari rangkaian proses yangbisa dilihat dari proses penilaian hasil belajar pengolahan data pada KDD.Data Mining bidang ilmu seperti penilaian harian terhadap siswa dalam hal ini yang tidak berdiri sendiri karena Data Mining memiliki bisa berupa tugas-tugas, ulangan harian dan lain-lain.

keterkaitan dengan bidang ilmu lainnya [2]. Metodemetode yang dapat digunakan dalam Data Mining adalah klasifikasi, regresi, seleksi variabel, market basket analisis dan clustering [3].

Perubahan pola pembelajaran siswa yang dilaksanakan secara daring pada masa pandemi inilah yang menjadi dasar penelitian ini, sehingga dapat dilakukan analisa terhadap hasil belajar siswa. Metode C4.5 digunakan Algoritma C4.5 adalah algoritma yang sudah banyak untuk menganalisa data nilai hasil belajar siswa yang dikenal dan digunakan untuk klasifikasi data yang dilaksanakan pada masa pandemi, sehingga dari data memiliki atribut-atribut numerik dan kategorial [4]. nilai yang ada bisa digunakan untuk memprediksi hasil Metode C4.5 banyak digunakan pada penelitian di belajar siswa dan knowledge yang didapatkan bisa bidang pendidikan. Metode C4.5 untuk memprediksi menjadi pertimbangan untuk kebijakan di sekolah dan pekerjaan lulusan perguruan tinggi serta menganalisa bisa meningkatkan hasil pembelajaran.

faktor-faktor yang mempengaruhi lulusan perguruan tinggi mendapatkan pekerjaan dan kualitas dari pekerjaan tersebut [5]. Algoritma C4.5 digunakan untuk memprediksi siswa dalam memperoleh bantuan danapendidikan [6]. Algoritma C4.5 dimanfaatkan pada penerapan Educational Data Mining untuk memprediksi hasil belajar siswa SMAK Ora et Labora [7].

Tujuan yang akan dicapai pada penelitian ini adalah memahami Metode C4.5 untuk memprediksi hasil belajar siswa secara daring pada masa pandemi COVID-19 di SMK Negeri 2 Padang Panjang.Kemudian menganalisa nilai hasil belajar siswa secara daring pada masa pandemi COVID-19 untuk mendapatkan knowledge yang dihasilkan dari data nilai hasil belajar siswa tersebut disertai variabelPenelitian-penelitian sebelumnya yang menggunakan variabel pembentuknya. Setelah itu menguji Metode Metode C4.5 adalah implementasi Decision Tree untuk C4.5 untuk hasil belajar siswa pada masa pandemi prediksi kelulusan mahasiswa tepat waktu [8]. COVID-19 dengan menggunakan Software Rapid Memprediksi mahasiswa yang berpotensi non aktif Miner Studio 9.2.0.

menggunakan Data Mining dalam DecisionTree dan Algoritma C4.5 [9]. Mengatasi permasalahan pemberian beasiswa yang kurang adil dan tidak efisien dengan membuat sistem evaluasi beasiswa mahasiswa menggunakan pohon keputusan C4.5 [10].

Penerapan Metode C4.5 pada penelitian lainnya adalah sistem prediksi dan evaluasi prestasi akademik mahasiswa menggunakan Data Mining, di mana klasifikasi dilakukan untuk menemukan faktor-faktor yang mempengaruhi prestasi mahasiswa [11]. Mengidentifikasi faktor-faktor yang mempengaruhi Kerangka kerja penelitian dibuat untuk memudahkan jenis kecelakaan dengan menggunakan Algoritma C4.5 penulis dalam melakukan penelitian agar lebih mudah [12]. Menggabungkan Algoritma C4.5 dengan dipahami dan tidak keluar dari pokok Algoritma Relief-F untuk mengatasi permasalahan pembahasan.Langkah-langkah yang dibuat dalam status stabilitas tegangan sistem agar dapat kerangka kerja penelitian disusun secara sistematis diidentifikasi secara online [13].

Pembelajaran daring walaupun tidak lagi pandemi guna menyelesaikan permasalahan yang ada.Alur kerangka kerja penelitian dapat dilihat pada Gambar 1. namun tetap akan dipertahankan dengan dengan polapola tertentu. Pandemi COVID-19 menjadi tonggak perubahan pembelajaran menjadi daring, diperkirakan sebagian besar pembelajaran beberapa disiplin ilmu tetap akan dilakukan online bahkan setelah COVID-19 [14]. Siswa mengalami penurunan semangat belajar selama pembelajaran daring di masa pandemi COVID- 


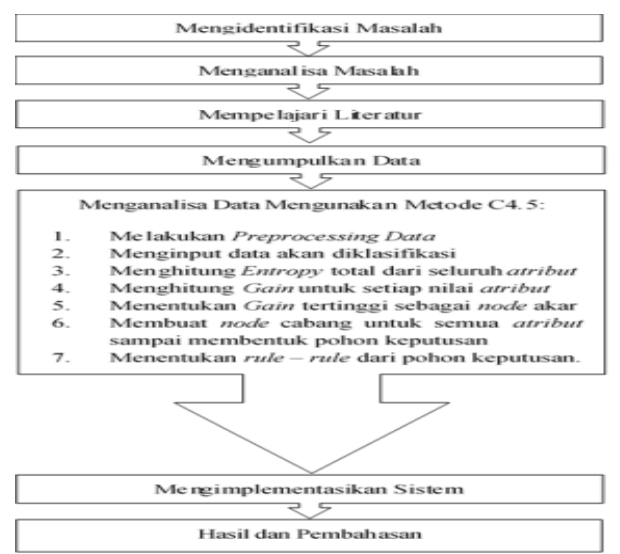

Gambar 1. Kerangka Kerja Penelitian

\subsection{Mengimplementasikan Sistem}

Implementasi dilakukan untuk mendapatkan pola terbaik dalam penelitian dalam hal terhadap penentuan kriteria hasil belajar siswa yang "memuaskan" dan "tidak memuaskan", dengan menggunakan data training dan dibandingkan dengan data testing. Metode C4.5 menggunakan Tools Data Mining dan untuk penelitian ini menggunakan Software Rapid Miner Studio 9.2.0.

\subsection{Hasil dan Pembahasan}

Hasil perhitungan Metode C4.5 tersebut nantinya akan terdapat rule-rule yang dihasilkan, kemudian dilakukan pengujian hasil yang diperoleh dari perhitungan manual tersebut dibandingkan dengan hasil dari Software Rapid Berdasarkan kerangka kerja penelitian pada gambar Miner Studio 9.2.0. Data training dan data testing dapat diuraikan masing-masing langkahnya sebagai diuji coba terhadap rule untuk mendapatkan nilai berikut:

\subsection{Mengidentifikasi Masalah}

Tahap identifikasi masalah merupakan tahapan awal penelitian.Peneliti melakukan perumusan masalah dari kondisi hasil belajar siswa pada pembelajaran yang dilaksanakan secara daring masa pandemi COVID-19.

\subsection{Menganalisa Masalah}

Pada tahapan ini menganalisa kondisi penilaian hasil belajar pada masa pandemi COVID-19, supaya dapat diketahui variabel-variabel penilaian apa saja yang mempengaruhi hasil belajar siswa.

\subsection{Mempelajari Literatur}

Mempelajari literatur juga sangat penting dilakukan agar mempunyai landasan baik secara teoritis yang benar dan dijelaskan oleh para peneliti dan ahli sebelumnya. Kemudian literatur-literatur yang dipelajari tersebut diseleksi dan dipilih literatur mana yang akan digunakan dalam penelitian. Literatur yang diambil dari berbagai sumber yaitu berupa buku, artikel, jurnal ilmiah tentang Algoritma C4.5, Data mining, serta bacaan lain yang mendukung.

\subsection{Mengumpulkan Data}

Pengumpulan data dilakukan agar dapat memperoleh informasi sehingga tujuan dari penelitian menggunakan Metode C4.5 ini dapat tercapai.Pengumpulkan data dengan melakukan observasi langsung di SMKN 2 Padang Panjang. Pengamatan secara langsung dilokasi penelitian untuk melihat data yang akan diproses dan data yang diambil merupakan data nilai siswa di SMK Negeri 2 Padang Panjang.

\subsection{Menganalisa Data Menggunakan Metode C4.5}

Analisa data dengan Metode C4.5 digunakan untuk memprediksi hasil belajar siswa secara daring pada masa pandemi COVID-19. Sebelum dianalisa dengan Metode C4.5, data yang dikumpulkan melalui tahap preprocessing (data cleaning dan transformation) terlebih dahulu, sehingga menghasilkan data set berupa data training dan data testing. Setelah itu dilanjutkan dengan analisa data menggunakan Metode C4.5. akurasinya. Hasil rule dan knowledgenya dapat digunakan untuk rekomendasi kebijakan di sekolah.

\section{Hasil dan Pembahasan}

\subsection{Data}

Objek yang diolah pada penelitian ini adalah nilai hasil belajar siswa pada Penilaian Tengah Semester (PTS) Semester Ganjil Tahun Pelajaran 2020/2021 yang merupakan puncak dari pandemi COVID-19 dan pembelajaran siswa semuanya dilaksanakan secara daring.

Data penelitian didapatkan dari data nilai siswa yang ada di Tata Usaha SMKN 2 Padang Panjang. Data yang digunakan pada penelitian adalah data nilai mata pelajaran Desain Media Interaktif (DMI), dengan data sampel 61 orang siswa kelas XII program Keahlian Multimedia yang terdiri dari 2 kelas yaitu 1 kelas sebagai data training dan 1 kelas sebagai data testing. Data nilai DMI menjadi sampel mata pelajaran yang akan diklasifikasi untuk dapat memprediksi nilai hasil belajar pada mata pelajaran yang pelaksanaan pembelajarannya berada di masa pandemi COVID-19.

Data nilai yang dianalisa adalah nilai hasil belajar pada Penilaian Tengah Semester (PTS) Ganjil mata pelajaran DMI disertai variabel-variabel yang mempengaruhi hasil nilai mata pelajaran tersebut. Hasil belajar yang akan diprediksi berdasarkan nilai hasil PTS yang merupakan pengolahan dari beberapa item data nilai yang ada penilaian pembelajaran siswa yang diambil pada saaat pembelajaran daring pada masa pandemi. Penelitian menggunakan data nilai mata pelajaran untuk memprediksi nilai hasil belajar siswa pada masa pandemi kepada salah satu mata pelajaran sebagai sampel data dengan menganalisa data nilai menggunakan metode $\mathrm{C} 4.5$ dengan melihat atributatribut langsung atau data internal yang berpengaruh langsung terhadap penilaian hasil belajar tersebut.

\subsection{Analisa Sistem (Metode C4.5)}

Metode C4.5 merupakan salah satu metode yang dapat digunakan untuk melakukan klasifikasi data dan kemudian rule yang didapatkan dari klasfikasi data tersebut dapat digunakan untuk melakukan prediksi. 
Sistem yang akan dibangun dengan Metode C4.5 dalam Tabel 2 merupakan atribut penunjang yang terdiri dari penelitian ini adalah melakukan klasifikasi terhadap 4 atribut. Atribut penunjang pada Tabel 2 memerlukan data nilai hasil belajar siswa sehingga menghasilkan beberapa perubahan pada atribut dan nilai atribut rule-rule yang dapat digunakan untuk memprediksi sehingga dapat memudahkan pada saat dilakukan hasil belajar siswa secara daring pada masa pandemi pengolahan data menggunakan Algoritma C4.5. Atribut COVID-19.

Algoritma C4.5 menganalisa data yang ada dengan melakukan perhitungan entropy dan Gain sehingga menemukan Node dan Leaf yang akan membentuk pohon keputusan. Pohon keputusan menghasilkan rulerule dapat digunakan pada data lain untuk memprediksi hasil belajar siswa pada masa pandemi COVID19.Pengolahan data menggunakan Algoritma C4.5 untuk nilai hasil belajar siswa dimasa pandemi dan rule-rule yang dihasilkan dari analisa data dengan metode C4.5 dapat digunakan untuk memprediksi hasil belajar siswa.

Penerapan Algoritma C4.5 dalam penelitian digambarkan dengan diagram proses agar lebih terarah dan mudah dipahami. Diagram akan menggambarkan langkah-langkah perhitungan metode C4.5 dalam menghasilkan pohon keputusan. Diagram proses untuk Algoritma C4.5 penelitian terdapat pada Gambar 2.

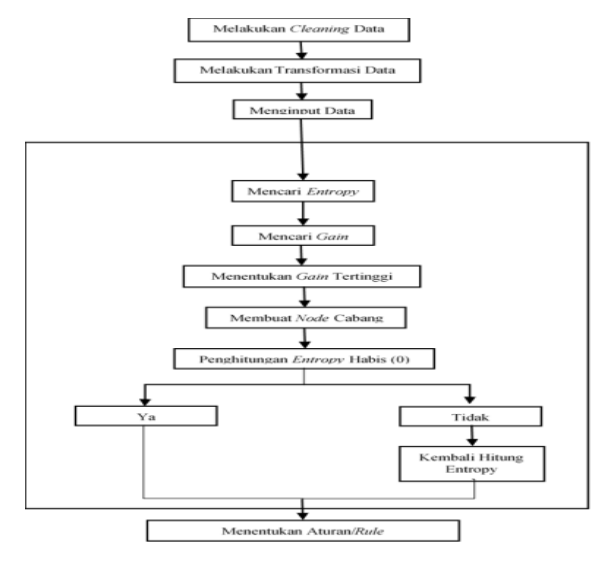

Gambar 2. Diagram Proses Algoritma C4.5 penunjang yang digunakan pada penelitian ini merupakan atribut-atribut yang menentukan nilai atribut keputusan disajikan pada Tabel1 sampai dengan Tabel 3.

Tabel 1. Kriteria Keputusan dan Hasil Belajar

\begin{tabular}{ccl}
\hline $\begin{array}{c}\text { Kriteria hasil } \\
\text { belajar }\end{array}$ & $\begin{array}{c}\text { Nilai } \\
\text { Atribut }\end{array}$ & \multicolumn{1}{c}{ Deskripsi } \\
\hline & Memuaskan & $\begin{array}{l}\text { Kriteria hasil } \\
\text { belajarmemuask } \\
\text { an jika nilai } \geq 65 \\
\text { Kriteria hasil } \\
\text { belajarkurang } \\
\text { memuaskan jika } \\
\text { nilai }<65\end{array}$ \\
\hline
\end{tabular}

Tabel 2. Atribut Penunjang dan Parameter

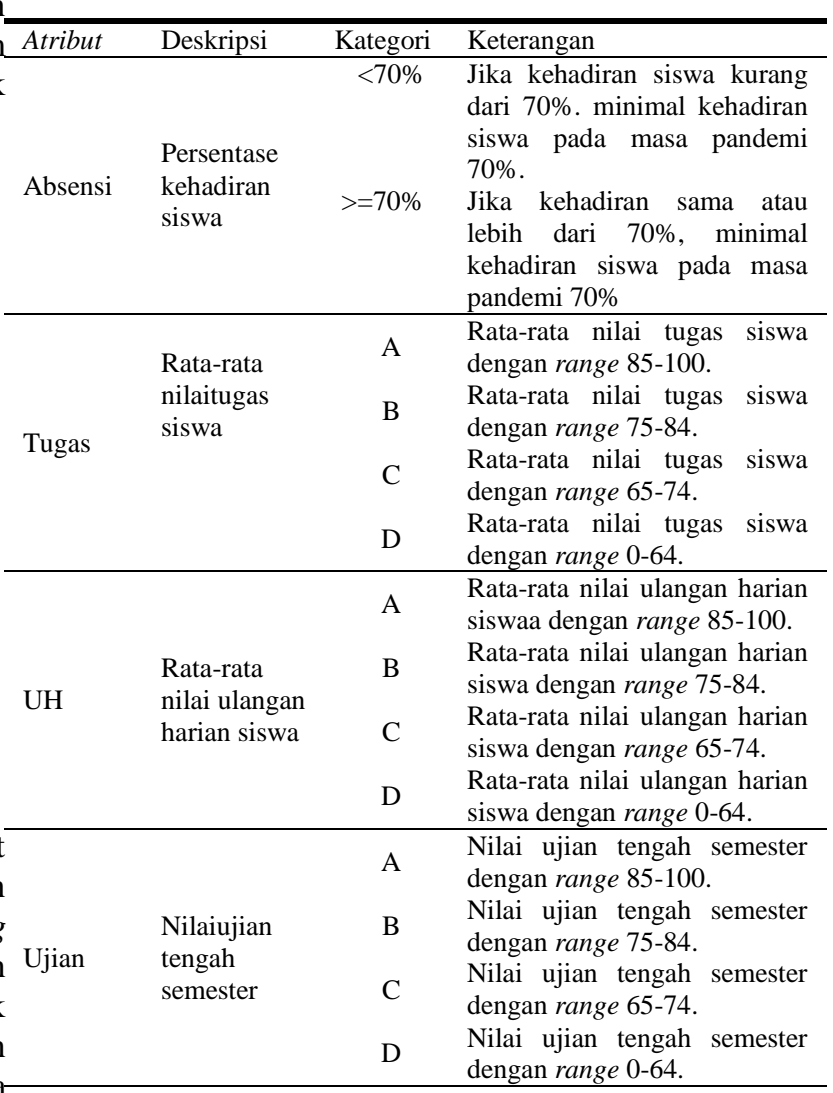

\subsubsection{Processing dan Transformasi Data}

Sebelum dilakukan pengolahan data, data tersebut sudah dalam keaadaan bersih dan siap untuk digunakan dengan melakukan cleaning data. Data cleaning dilakukan menentukan data-data mana saja yang akan dipergunakan karena pada data awal terdapat banyak data dan tidak semua atribut data yang akan digunakan maka dilakukan cleaning data, seperti pada data tersebut terdapat Nomor Induk Siswa (NIS) dan jenis kelamin.

Tabel 1 merupakan transformasi dan deskripsi untuk hasil belajar siswa yang menggunakan 1 Atributsebagai atribut target (Keputusan=Memuaskan atau Keputusan=Kurang memuaskan). Keputusan untuk hasil belajar siswa diambil dari data Nilai DMI untuk Penilaian Tengah Semester (PTS) siswa. Data nilai siswa tersebut kemudian ditransfromasi dengan memberikan rangeatribut keputusan. Range yang digunakan pada keputusan hasil belajar siswa mengacu kepada Kriteria Ketuntasan Minimal (KKM) mata pelajaran Kejuruan di SMKN 2 Padang Panjang.

Tabel 3. Hasil Transformasi Data Training

\begin{tabular}{ccccc}
\hline Absensi & Tugas & UH & Ujian & Hasil Belajar \\
\hline$<70 \%$ & B & A & A & Memuaskan \\
$>=70 \%$ & A & A & B & Memuaskan \\
$>=70 \%$ & D & B & D & Kurang Memuaskan \\
$>=70 \%$ & A & A & C & Memuaskan \\
$<70 \%$ & D & B & B & Kurang Memuaskan \\
$>=70 \%$ & D & A & C & Memuaskan \\
$>=70 \%$ & A & A & B & Memuaskan \\
$>=70 \%$ & D & A & D & Memuaskan \\
$>=70 \%$ & A & A & D & Memuaskan \\
$>=70 \%$ & D & D & D & Kurang Memuaskan \\
& & & & \\
\hline
\end{tabular}


Hasil dari transfomasi data siswa berupa data training dengan perhitungan Gain semua atribut, yang dapat dilihat pada Tabel 3. Data training terdiri dari 31 ditampilkan hanya 1 atribut.

data nilai siswa, yang ditampilkan hanya 10 data.

\subsubsection{Pengolahan data}

a. Mencari Node 1

Langkah awal dalam membentuk pohon keputusan dengan Algoritma C4.5 adalah dengan melakukan beberapa perhitungan untuk membentuk node 1, yaitu menghitung Entropy Total, Entropy masing-masing atribut dan Gain untuk semua atribut.Hasil perhitungannya ditampilkan pada Tabel 4.

Tabel 4. Perhitungan Node 1

\begin{tabular}{|c|c|c|c|c|c|c|c|}
\hline $\begin{array}{l}\text { No } \\
\text { de }\end{array}$ & & & $\mathrm{S}$ & S1 & $\mathrm{S} 2$ & $\mathrm{E}$ & G \\
\hline \multirow[t]{19}{*}{1} & Total & & 31 & 23 & 8 & 0,8238 & \multirow{4}{*}{0,2982} \\
\hline & Absensi & & & & & & \\
\hline & \multirow{4}{*}{ Tugas } & $<70 \%$ & 8 & 2 & 6 & 0,8113 & \\
\hline & & $>=70 \%$ & 23 & 21 & 2 & 0,4262 & \\
\hline & & & & & & & \multirow[t]{2}{*}{0,2804} \\
\hline & & A & 11 & 11 & 0 & 0,0000 & \\
\hline & & B & 6 & 5 & 1 & 0,6500 & \multirow{8}{*}{$\mathbf{0 , 4 3 3 5}$} \\
\hline & & $\mathrm{C}$ & 1 & 1 & 0 & 0,0000 & \\
\hline & & D & 13 & 6 & 7 & 0,9957 & \\
\hline & \multirow[t]{5}{*}{ UH } & & & & & & \\
\hline & & A & 18 & 18 & 0 & 0,0000 & \\
\hline & & B & 4 & 1 & 3 & 0,8113 & \\
\hline & & $\mathrm{C}$ & 4 & 2 & 2 & 1,0000 & \\
\hline & & D & 5 & 2 & 3 & 0,9710 & \\
\hline & \multirow[t]{5}{*}{ Ujian } & & & & & & \multirow[t]{5}{*}{0,1914} \\
\hline & & A & 4 & 4 & 0 & 0,0000 & \\
\hline & & B & 7 & 6 & 1 & 0,5917 & \\
\hline & & $\mathrm{C}$ & 9 & 8 & 1 & 0,5033 & \\
\hline & & D & 11 & 5 & 6 & 0,9940 & \\
\hline
\end{tabular}

Perhitungan tiap nodesama tahapannya sama seperti dimulai dengan perhitungan Entropy dan Gain. Berikut rumus perhitungan Entropy.

$$
\text { Entropy }(S)=\sum_{1-i}^{n}-p i * \log _{2} p i
$$

Dimana Sadalah Jumlah sampel data (sampling), $n$ adalah Jumlah partisi S, dan pi merupakan Proporsi dari Si terhadap S.

\section{Entropy (Total)}

$$
\begin{aligned}
& =\left(-\frac{23}{31} * \log 2\left(\frac{23}{31}\right)\right) \\
& +\left(-\frac{8}{31} * \log 2\left(\frac{8}{31}\right)\right)=0,8238
\end{aligned}
$$

Entropy $(<70 \%)$

$$
\begin{aligned}
& =\left(-\frac{2}{8} * \log 2\left(\frac{2}{8}\right)\right) \\
& +\left(-\frac{6}{8} * \log 2\left(\frac{6}{8}\right)\right)=0,8113
\end{aligned}
$$

Entropy (>=70\%)

$$
\begin{aligned}
& =\left(-\frac{21}{23} * \log 2\left(\frac{21}{23}\right)\right) \\
& +\left(-\frac{2}{23} * \log 2\left(\frac{2}{23}\right)\right)=0,4262
\end{aligned}
$$

Perhitungan entropy tiap nilai atribut (variabel atribut) berlaku untuk semua atribut. Perhitungan yang ditampilkan hanya 1 atribut saja. Kemudian dilanjutkan
Gain (Total, Absensi)

$$
=\text { Entropy }(\text { Total })-\sum_{1-n}^{n} \frac{\text { Absensi }}{\text { Total }}
$$

Gain (Total, Absensi)

$$
\begin{aligned}
& =0,8238 \\
& -\left(\left(\frac{8}{31} * 0,8113\right)\right. \\
& \left.+\left(\frac{23}{31} * 0,4262\right)\right)=0,2982
\end{aligned}
$$

Tabel 4 perhitungan Node 1 memperlihatkan Gain tertinggi adalah pada atribut $\mathrm{UH}$ dengan nilai $=0,4335$ dan menjadi node akar untuk penghitungan algoritma $\mathrm{C}$ 4.5 berikutnya. Atribut UH dengan nilai atribut "A" mempunyai keputusan "Memuaskan". Atribut UH dengan nilai atribut " $\mathrm{B}$ ", "C" dan "D" masih

\begin{tabular}{|c|c|c|c|c|c|c|c|}
\hline $\begin{array}{c}\text { No } \\
d e\end{array}$ & & & $\mathrm{~S}$ & S1 & $\mathrm{S} 2$ & $\mathrm{E}$ & G \\
\hline \multirow[t]{4}{*}{1.1} & $\mathrm{UH}$ & B & 4 & 1 & 3 & 0,8113 & \\
\hline & Absensi & & & & & & 0,3113 \\
\hline & & $<70 \%$ & 2 & 0 & 2 & 0,0000 & \\
\hline & & $>=70 \%$ & 2 & 1 & 1 & 1,0000 & \\
\hline
\end{tabular}
mempunyai nilai yang akan dihitung, dan menjadi cabang untuk perhitungan pohon keputusan selanjutnya. Pohon keputusan awal ditampilkan pada Gambar 3.

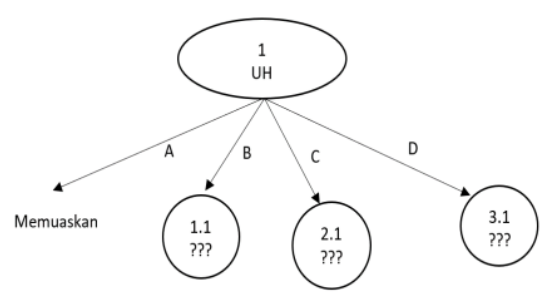

Gambar 3. Pohon Keputusan Awal

\section{b. Mencari Node 1.1}

Proses pencarian node 1.1 tahapannya sama dengan node 1 dan hasil perhitungan Entropydan Gainnya berada pada Tabel 5 .

Tugas

$\mathbf{0 , 8 1 3 3}$

$\begin{array}{lllll}\text { A } & 0 & 0 & 0 & 0,0000 \\ \text { B } & 1 & 1 & 0 & 0,0000 \\ \text { C } & 0 & 0 & 0 & 0,0000 \\ \text { D } & 3 & 0 & 3 & 0,0000\end{array}$

Ujian

$\begin{array}{lllll}\text { A } & 0 & 0 & 0 & 0,0000 \\ \text { B } & 1 & 0 & 1 & 0,0000 \\ \text { C } & 0 & 0 & 0 & 0,0000 \\ \text { D } & 3 & 1 & 2 & 0,9183\end{array}$


Tabel 5 memperlihatkan Gain tertinggi adalah atribut d. Mencari Node 3.1

Tugas yang akan menjadi cabang akar untuk pohon keputusan selanjutnya, dengan nilai Gain adalah 0.8113. "Tugas_B" sudah mempunyai keputusan

"Memuaskan", dan "Tugas_D” mempunyai keputusan

"Tidak Memuaskan".

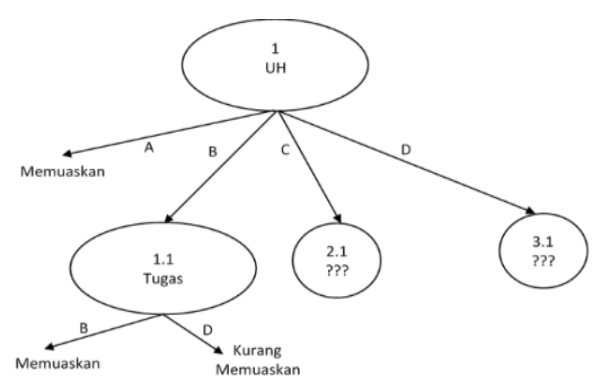

Gambar 4. Pohon Keputusan Node 1.1

c. Mencari Node 2.1

Perhitungan untuk node 2.1 merupakan perulangan dengan pola yang sama seperti node 1 dan node 1.1 .

Tabel 6. Perhitungan Node 2.1

\begin{tabular}{|c|c|c|c|c|c|c|c|}
\hline $\begin{array}{l}\text { No } \\
d e\end{array}$ & & & $\mathrm{~S}$ & S1 & $\mathrm{S} 2$ & $\mathrm{E}$ & G \\
\hline \multirow[t]{14}{*}{2.1} & UH & $\mathrm{C}$ & 4 & 2 & 2 & 1,0000 & \multirow{4}{*}{1,0000} \\
\hline & \multirow[t]{3}{*}{ Absensi } & & & & & & \\
\hline & & $<70 \%$ & 2 & 0 & 2 & 0,0000 & \\
\hline & & $>=70 \%$ & 2 & 2 & 0 & 0,0000 & \\
\hline & \multirow[t]{5}{*}{ Tugas } & & & & & & \\
\hline & & A & 0 & 0 & 0 & 0,0000 & \multirow{9}{*}{0,5000} \\
\hline & & B & 1 & 1 & 0 & 0,0000 & \\
\hline & & $\mathrm{C}$ & 0 & 0 & 0 & 0,0000 & \\
\hline & & D & 3 & 1 & 2 & 0,9183 & \\
\hline & \multirow[t]{5}{*}{ Ujian } & & & & & & \\
\hline & & A & 0 & 0 & 0 & 0,0000 & \\
\hline & & B & 1 & 1 & 0 & 0,0000 & \\
\hline & & $\mathrm{C}$ & 1 & 0 & 1 & 0,0000 & \\
\hline & & D & 2 & 1 & 1 & 1,0000 & \\
\hline
\end{tabular}

Hasil perhitungan pada Tabel 6 merupakan perhitungan pencarian Entropy, Gain dan memilih gain tertinggi sebagai node akar sama halnya seperti pada node 1 dan node 1.1 .

Proses perhitungan node 2.1 untuk Entropydan Gain pada Tabel 6 yang mempunyai nilai Gain tertinggi adalah Absensi dengan nilai gain sebesar 1,0000. Selanjutnya atribut Absensi dengan nilai atribut $<70 \%$ mempunyai keputusan "Kurang Memuaskan" dan atribut Absensi dengan nilai atribut $>=70 \%$ mempunyai keputusan "Memuaskan" akan menjadi cabang akar untuk pohon keputusan selanjutnya, maka pohon keputusan yang terbentuk adalah seperti Gambar 5.

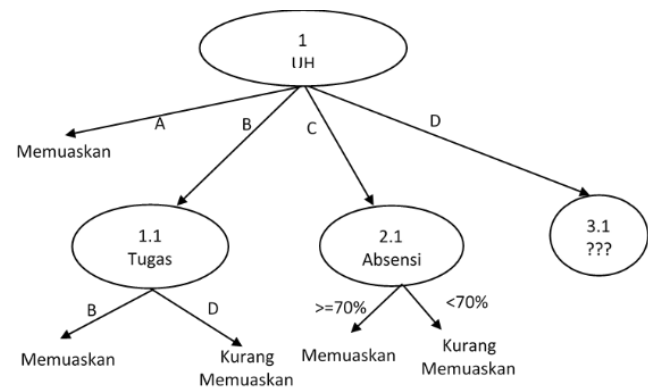

Gambar 5. Pohon Keputusan Node 2.1
Perhitungan selanjutnya adalah untuk atribut "UH_D", karena cabang akarnya untuk node 3.1 masih memerlukan keputusan yang tepat.

Tabel 7. Perhitungan Node 3.1

\begin{tabular}{|c|c|c|c|c|c|c|c|}
\hline $\begin{array}{l}\text { No } \\
\text { de }\end{array}$ & & & $S$ & S1 & S2 & $\mathrm{E}$ & G \\
\hline \multirow[t]{14}{*}{3.1} & UH & $\mathrm{D}$ & 5 & 2 & 3 & 0,9710 & \multirow{4}{*}{0,0200} \\
\hline & \multirow[t]{3}{*}{ Absensi } & & & & & & \\
\hline & & $<70 \%$ & 3 & 2 & 1 & 0,9183 & \\
\hline & & $>=70 \%$ & 2 & 1 & 1 & 1,0000 & \\
\hline & \multirow[t]{5}{*}{ Tugas } & & & & & & \multirow[t]{5}{*}{0,5710} \\
\hline & & A & 0 & 0 & 0 & 0,0000 & \\
\hline & & B & 2 & 1 & 1 & 1,0000 & \\
\hline & & $\mathrm{C}$ & 1 & 1 & 0 & 0,0000 & \\
\hline & & D & 2 & 0 & 2 & 0,0000 & \\
\hline & \multirow[t]{5}{*}{ Ujian } & & & & & & \multirow[t]{5}{*}{0,9710} \\
\hline & & A & 0 & 0 & 0 & 0,0000 & \\
\hline & & B & 1 & 1 & 0 & 0,0000 & \\
\hline & & $\mathrm{C}$ & 1 & 1 & 0 & 0,0000 & \\
\hline & & $\mathrm{D}$ & 3 & 0 & 3 & 0,0000 & \\
\hline
\end{tabular}

Proses perhitungan node 3.1 untuk entropy dan gain terlihat pada Tabel7, yang mempunyai nilai Gain tertinggi adalah atribut Ujian dengan nilai gain sebesar 0,9710. Selanjutnya atribut Ujian dengan nilai atribut B mempunyai keputusan "Memuaskan", atribut Ujian dengan nilai atribut $\mathrm{C}$ mempunyai keputusan "Memuaskan" dan atribut Absensi dengan nilai atribut D mempunyai keputusan "Kurang Memuaskan" akan menjadi cabang akar untuk pohon keputusan selanjutnya, maka pohon keputusan yang terbentuk adalah seperti Gambar 6 .

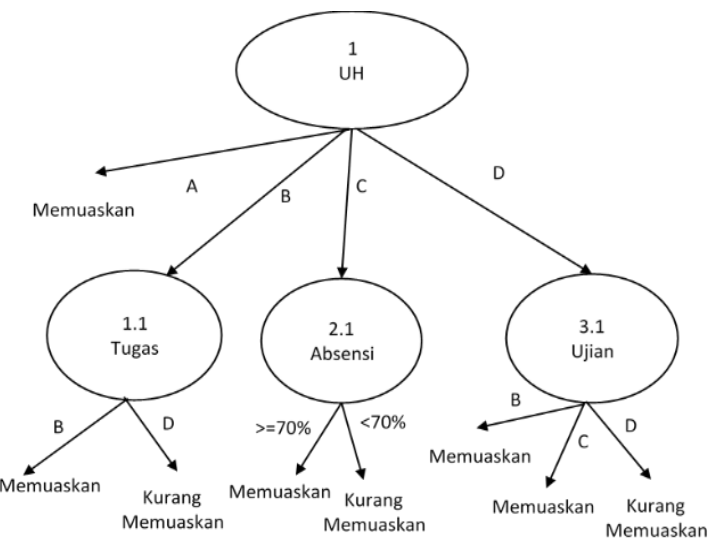

Gambar 6. Pohon Keputusan Node 3.1

Gambar 6 merupakan pohon keputusan dengan akar cabang terakhir karena setiap node cabang sudah habis atau mempunyai keputusan masing-masing. Pohon keputusan tersebut sudah dapat menghasilkan rule dan knowledge.

Berdasarkan pohon keputusan terakhir yang terbentuk pada Gambar 6, maka rule-rule keputusan yang dihasilkan dijabarkan pada Tabel 8. 
Tabel 8. Daftar Aturan (Rule) Pohon Keputusan Akhir

\begin{tabular}{cl}
\hline No & \multicolumn{1}{c}{ Aturan (Rule) } \\
\hline 1 & IF UH = A \\
& THEN Keputusan Memuaskan \\
\hline 2 & IF UH = B \\
& AND Tugas = B \\
& THEN Keputusan Memuaskan \\
\hline 3 & IF UH = B \\
& AND Tugas = D \\
& THEN Keputusan Kurang Memuaskan \\
\hline 4 & IF UH = C \\
& AND Absensi = >=70\% \\
& THEN Keputusan Memuaskan \\
\hline 5 & IF UH = C \\
& AND Absensi = <70\% \\
& THEN Keputusan Kurang Memuaskan \\
\hline 6 & IF UH = D \\
& AND Ujian = B \\
& THEN Keputusan Memuaskan \\
\hline 7 & IF UH = D \\
& AND Ujian = C \\
& THEN Keputusan Memuaskan \\
\hline 8 & IF UH = D \\
& AND Ujian = D \\
& THEN Keputusan Kurang Memuaskan \\
\hline
\end{tabular}

Penelitian yang dilakukan dengan Metode C4.5 terhadap data nilai hasil belajar siswa di masa pandemi menghasilkan rule-rule keputusan yang ditampilkan pada Tabel 8. Rule-rule keputusan tersebut bisa digunakan untuk memprediksi hasil belajar siswa pembelajaran daring suatu mata pelajaran pada masa pandemi COVID-19 di SMKN 2 Padang Panjang.

Selanjutnya dilakukan pengujian terhadap data nilai hasil belajar siswa menggunakan software Rapid Miner Studio 9.2.0. Pengujian dilakukan untuk mengetahui kecocokan hasil klasifikasi output dan pohon keputusannya.

\section{Tree}

$\mathrm{UH}=\mathrm{A}:$ Memuaskan $\{$ Memuaskan $=18$, Kurang Memuaskan $=0$

$\mathrm{UH}=\mathrm{B}$

Tugas = B: Memuaskan (Memuaskan=1, Kurang Memuaskan=0

Tugas $=\mathrm{D}$ : Kurang Memuaskan $\{$ Memuaskan=0, Kurang Memuaskan=3

$=0$

Absensi $=\langle 70$ : $:$ Kurang Memuaskan $\{$ Memuaskan=0, Kurang Memuaskan=2 Absensi $=>=70$ : : Memuaskan $\{$ Memuaskan=2, Kurang Memuaskan $=0$ \} $=\mathrm{D}$

Ujian = B: Memuaskan \{Memuaskan=1, Kurang Memuaskan=0

$\mathrm{Uj}$ jan $=\mathrm{C}:$ Memuaskan (Memuaskan=1, Kurang Memuaskan=0\}

$\mathrm{Uj} i a n=\mathrm{D}$ : Kurang Memuaskan Memuaskan=0, Kurang Memuaskan=3,

Gambar 7. Klasifikasi Output Pengujian RapidMiner

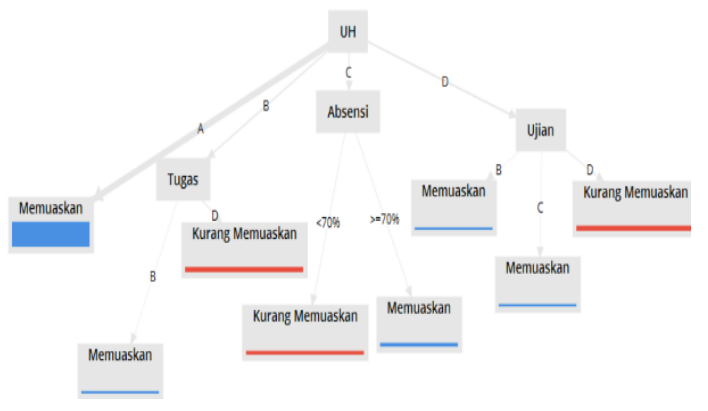

Gambar 8. DecisionTree hasil RapidMiner 9.2.0

Rule-rule hasil pengujian RapidMiner Studio 9.2.0:

1. $\mathrm{IF} \mathrm{UH}=\mathrm{A}, \mathrm{THEN}$ Keputusan Memuaskan
2. $\mathrm{IF}$ UH $=$ B AND Tugas $=$ B, THEN Keputusan Memuaskan

3. $\mathrm{IF} \mathrm{UH}=\mathrm{BAND}$ Tugas $=\mathrm{D}$, THEN Keputusan Kurang Memuaskan

4. IF UH $=$ CAND Absensi $=>=70 \%$, THEN Keputusan Memuaskan

5. $\mathrm{IF}$ UH $=\mathrm{C}$ AND Absensi $=<70 \%$, THEN Keputusan Kurang Memuaskan

6. IF UH $=$ DAND Ujian $=$ B, THEN Keputusan Memuaskan

7. IF UH $=$ DAND Ujian $=\mathrm{C}$, THEN Keputusan Memuaskan

8. IF UH $=$ DAND Ujian $=$ D, THEN Keputusan Kurang Memuaskan

Pengujian dengan menggunakan RapidMiner Studio 9.2.0 menghasilkan klasifikasi outputrule dan pohon keputusan yang sama dengan hasil perhitungan manual C4.5. Klasifikasi output dan rule ditampilkan pada Gambar 7, sedangkan hasil pohon keputusan (DecisionTree) pada Gambar 8.

Setelah pengujian untuk rule pohon keputusan dilanjutkan dengan pengujian data testing menggunakan Software Rapid Miner. Data testing yang diuji sebanyak 30 data nilai siswa.

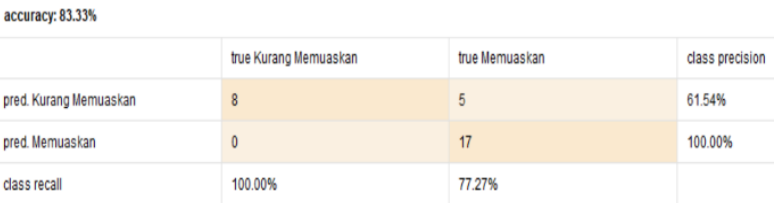

Gambar 9. Hasil Pengujian Data Testing

Pengujian data testing dengan Rapid Miner Studio 9.2.0 berada pada Gambar 9.

1. Accuracy: $83,33 \%$.

2. Precision: Prediksi "Kurang Memuaskan" 61,54\%, Prediksi "Memuaskan" 100\%.

3. Class Recall: "Kurang Memuaskan" 100\%, "Memuaskan" 77,27\%.

\section{Kesimpulan}

Berdasarkan penelitian dan pembahasan yang dilakukan dapat diambil kesimpulan yaitu: Klasifikasi Metode C4.5 terhadap nilai hasil belajar siswa menghasilkan rule-rule dan knowledge yang dapat digunakan untuk memprediksi hasil belajar siswa secara daring pada masa pandemi COVID-19. Pengujian yang dilakukan dengan Software RapidMiner Studio.9.2.0 mendapatkan akurasi sebesar 83,33\%, dengan nilai akurasi ini maka sudah dapat digunakan sebagai rekomendasi kebijakan di sekolah.

Penelitian selanjutnya dapat dilakukan dengan data yang lebih banyak untuk mendapatkan rule-ruleyang lebih bervariasi sehingga mendapatkan tingkat akurasi yang lebih baik. 


\section{Daftar Rujukan}

[1] Maulana, A., \& Fajrin, A. A. (2018). Penerapan Data Mining Untuk Analisis Pola Pembelian Konsumen Dengan Algoritma Fp-Growth Pada Data Transaksi Penjualan Spare Part Motor. Klik-Kumpulan Jurnal Ilmu Komputer, 5(1), 27. DOI: https://doi.org/10.20527/klik.v5i1.100 .

[2] Buulolo, Efori. (2020). Data Mining untuk Perguruan Tinggi. Yogyakarta: Deepublish. 6.

[3] Febianto, N. I., \& Palasara, N. (2019). Analisa Clustering KMeans Pada Data Informasi Kemiskinan di Jawa Barat Tahun 2018. Jurnal Sisfokom (Sistem Informasi dan Komputer), 8(2), 130. DOI: https://doi.org/10.32736/sisfokom.v8i2.653

[4] Elisa, E. (2017). Analisa dan Penerapan Algoritma C4.5 dalam Data Mining Untuk Mengidentifikasi Faktor-Faktor Penyebab Kecelakaan Kerja Kontruksi PT. Arupadhatu Adisesanti. Jurnal Online Informatika, 2(1). https://doi.org/10.15575/join.v2i1.71 .

[5] Zhou, F., Xue, L., Yan, Z., \& Wen, Y. (2020). Research on College Graduates Employment Prediction Model Based On C4.5 Algorithm. Journal of Physics: Conference Series, 1453. DOI: https://doi.org/10.1088/1742-6596/1453/1/012033 .

[6] Hendrian, S. (2018). Algoritma Klasifikasi Data Mining Untuk Memprediksi Siswa dalam Memperoleh Bantuan Dana Pendidikan. Faktor Exacta, 11(3). DOI: https://doi.org/10.30998/faktorexacta.v11i3.2777 .

[7] David, D. (2019). Penerapan Educational Data Mining Untuk Memprediksi Hasil Belajar Siswa SMAK Ora et Labora. Jurnal Ilmu Komputer, $12(2) . \quad$ DOI: https://doi.org/10.24843/jik.2019.v12.i02.p02 .

[8] Dengen, C. N., Kusrini, K., \& Luthfi, E. T. (2020). Implementasi Decision Tree Untuk Prediksi Kelulusan Mahasiswa Tepat Waktu. Jurnal Ilmiah SISFOTENIKA, 10(1). DOI: https://doi.org/10.30700/jst.v10i1.484 .

[9] Gaol, N. Y. L. (2020). Prediksi Mahasiswa Berpotensi Non Aktif Menggunakan Data Mining dalam Decision Tree dan Algoritma
C4.5. Jurnal Informasi dan Teknologi, 2(1), 23-29. DOI: https://doi.org/10.37034/jidt.v2i1.22 .

10]Wang, X., Zhou, C., \& Xu, X. (2019). Application of C4.5 Decision Tree for Scholarship Evaluations. Procedia Computer
Science,
151 ,
$179-184$.
DOI: https://doi.org/10.1016/j.procs.2019.04.027

[11]Rolansa, F., Yunita, Y., \& Suheri, S. (2020). Sistem Prediksi dan Evaluasi Prestasi Akademik Mahasiswa di Program Studi Teknik Informatika Menggunakan Data Mining. Jurnal Pendidikan Informatika dan Sains, 9(1). DOI: https://doi.org/10.31571/saintek.v9i1.1696 .

[12]Li, J., He, J., Liu, Z., Zhang, H., \& Zhang, C. (2019). Traffic Accident Analysis Based on C4.5 Algorithm in WEKA. MATEC Web of Conferences, 272. DOI: https://doi.org/10.1051/matecconf/201927201035 .

[13]Meng, X., Zhang, P., \& Zhang, D. (2020). Decision Tree for Online Voltage Stability Margin Assessment Using C4.5 and Relief-F Algorithms. Energies, 13(15). DOI: https://doi.org/10.3390/en13153824 .

14] Kumar, R. (2020). Assessing Higher Education in COVID-19 Era. Brock Education Journal, 29(2). DOI: https://doi.org/10.26522/brocked.v29i2.841

[15]Cahyani, A., Listiana, I. D., \& Larasati, S. P. D. (2020). Motivasi Belajar Siswa SMA pada Pembelajaran Daring di Masa Pandemi Covid-19. IQ (Ilmu Al-Qur'an): Jurnal Pendidikan Islam, 3(01), 123-140. DOI: https://doi.org/10.37542/iq.v3i01.57

16] Siahaan, M. (2020). Dampak Pandemi Covid-19 Terhadap Dunia Pendidikan. Jurnal Kajian Ilmiah, 1(1), 73-80. DOI: https://doi.org/10.31599/jki.v1i1.265 . 